PART I

Chapter 4

\title{
Global Boundaries of Health Care
}




\section{Introduction}

Achieving consensus on a common boundary of health care activities is crucial for the complex task of international comparisons. In pursuing this objective, SHA refers to a functional approach based on selected health care activities that can be captured by transactions. Transactions are valued activities that take place between different actors or organisations. The transactions recorded in the SHA accounting framework relate to health care goods and services provided and consumed to improve the health status of individuals and of the population as a whole.

It has to be emphasised that health itself is a condition, and is therefore not exchangeable, in contrast to health care. Health has value in use and not in exchange. Therefore, in health accounts, it is the demand, supply and distribution of health care goods and services, rather than health per se, that define the transactions measured. Consequently, the focus of this chapter is on the boundaries of health care, and not of health. ${ }^{1}$

In particular, this chapter focuses on the boundaries of health care activities that underlie the core accounting framework of SHA 2011. In addition, it introduces interfaces to the core accounting framework, which allow the compilation of a broader set of tables and indicators for useful analytical purposes and for exploring their relationships with other statistical systems.

\section{Defining current health care expenditures}

\section{Health care boundary: Focus on functions}

The functional classification of health care (ICHA-HC) delineates the boundaries of health care activities from an international perspective. ${ }^{2}$ Following the concept underlying the design of the ICHA-HC classification, the boundary contains all activities with the primary purpose of improving, maintaining and preventing the deterioration of the health status of persons and mitigating the consequences of ill-health through the application of qualified health knowledge [medical, paramedical and nursing knowledge, including technology, and traditional, complementary and alternative medicine (TCAM)]. This primary purpose is pursued by the following groups of health care activities:

- Health promotion and prevention;

- Diagnosis, treatment, cure and rehabilitation of illness;

- Caring for persons affected by chronic illness;

- Caring for persons with health-related impairment and disability;

- Palliative care;

- Providing community health programmes;

- Governance and administration of the health system.

In carrying out the above activities, the prerequisite of a basic level of medical, paramedical and nursing knowledge is one of the main delineation criteria. In most cases, 
but not exclusively, this refers to national standards of accreditation, licensing and other regulation or practices related to health care personnel and care givers. These procedures qualify them to practice their medical and nursing knowledge as well as to provide more complex services within an institutional framework.

Administration is an embedded activity in the provision of health care goods and services, for example, the administrative activities carried out in a hospital or a physician's practice, and as such it is included as an inherent part of the functions specified above. The functional classification does, however, distinguish separate categories of the health system governance and administration performed, for example, by ministries of health or health insurance enterprises, as follows:

- Governance and health system administration (HC.7.1): necessary for the design, operation, management and control of health care policy;

- Administration of health care financing (HC.7.2): necessary for managing the process of health care financing.

The basic dividing lines for structuring the health care functions are individual versus collective health care goods and services, the basic purposes of care (e.g. curative, rehabilitative, long-term care), and the modes of provision (e.g. inpatient, outpatient). SHA 2011 distinguishes (as did SHA 1.0) the health care functions (HC) and certain health carerelated functions (HCR). The latter can be closely linked to health care in terms of operations, institutions and personnel, but should, as far as possible, be excluded when measuring activities belonging to the health care functions themselves. For example, many activities that may accompany or follow the provision of health care services such as long-term social care or activities related to enhancing the social integration and participation of disabled persons are not counted as health care functions. Similarly, activities such as the control of food hygiene and drinking water, environmental protection and the multi-sector promotion of healthy life styles, which are well known as health determinants, should in general be recorded as health care-related functions and not health care functions, except in certain cases where there is a strict relation to preventive health care programmes.

\section{The core and extended accounts of SHA}

It is necessary to delineate a common boundary of the health care system that will permit international comparisons concerning both the amount and the structure of expenditures for health care goods and services. Central to the framework are three classifications related to health care functions, provision and financing, which will be subsequently referred to as the core classifications or the core framework. Other classifications complement these. In total, SHA 2011 distinguishes three main groups of classifications:

- The core framework, encompassing the three classifications that measure current health care expenditure by functions, providers and financing schemes;

- Capital formation, with its related classification of assets;

- And other classifications that allow for the compilation of additional indicators in the extension of the core accounting framework.

The core accounting framework is organised around a tri-axial system for the recording of health care expenditure, namely classifications of the functions of health care 
(ICHA-HC), health care provision (ICHA-HP), and financing schemes (ICHA-HF), ${ }^{3}$ as presented in Figure 4.1. These three core classifications address the three basic questions:

- What kinds of health care goods and services are consumed? (Chapter 5)

- Which health care providers deliver these goods and services? (Chapter 6)

- Which financing scheme pays for these goods and services? (Chapter 7)

The ultimate goal of data compilation of the core accounts is to answer these three questions with respect to each transaction that incurs health care expenditures - in other words, to use the three axes of the International Classifications for Health Accounts (ICHA), namely, function, provider and financing, to describe each financial flow in the health care sector.

Around the core accounting framework of the SHA, a number of complementary classifications might be added that are closely linked to one of the three axes. Some of these additional classifications, related to human resources, beneficiaries, revenues of financing schemes and factors for provision of health care, were introduced to varying extents in SHA 1.0 and/or in the Producers Guide, albeit in some cases with different names. SHA 2011 revisits some of these classifications with the aim of, inter alia: proposing a more comprehensive structure of classifications, as in the case of the beneficiary and factors of provision classifications; recommending a new breakdown to existing classifications, as in the classification of revenues of financing schemes; and offering better guidelines to particular aspects of health accounts, for instance, in the area of external trade in health care or capital formation, which are subjects of growing interest for both national and international policy. From an economic perspective, these classifications encompass activities that help to understand the health system in a wider context.

The health care functions of ICHA-HC refer to the health purpose of activities and determine the boundaries of health care consumption in the strict sense. The transactions related to the consumption of health care goods and services on the one hand and the transactions related to capital formation, education and training, as well as to research and development for future health care provision, on the other hand, serve different purposes. The first group of transactions relate to the current health expenditure account directly and serve the purpose of promoting, developing and maintaining the health status of individuals and the population as a whole. Here it should be noted that collective health care service provision is considered to be for the direct final use of health care by the community as a whole. The second group of activities are those relating to resource generation that have the purpose of supporting health care provision by developing technology, human resources and capital formation. In SHA 2011, these different purposes are clearly separated, while maintaining the tri-axial account of current health expenditures of SHA 1.0. As a consequence, the boundaries of the second type of transactions are included in extended expenditure accounts, whose boundaries relate to those of the first type (health care consumption) of transaction, but do not equate to them.

Figure 4.1 shows the core health expenditure accounts of SHA 2011 and their extensions. The three core classifications in the middle of this figure represent the consumption of health care goods and services, which equals their provision and financing. Each of the three dimensions provides interfaces to further breakdowns or dimensions. Details of the links between core and extended accounts are described in more detail in Part 2 and in the annexes. 
Figure 4.1. The core and extended accounting framework of SHA 2011

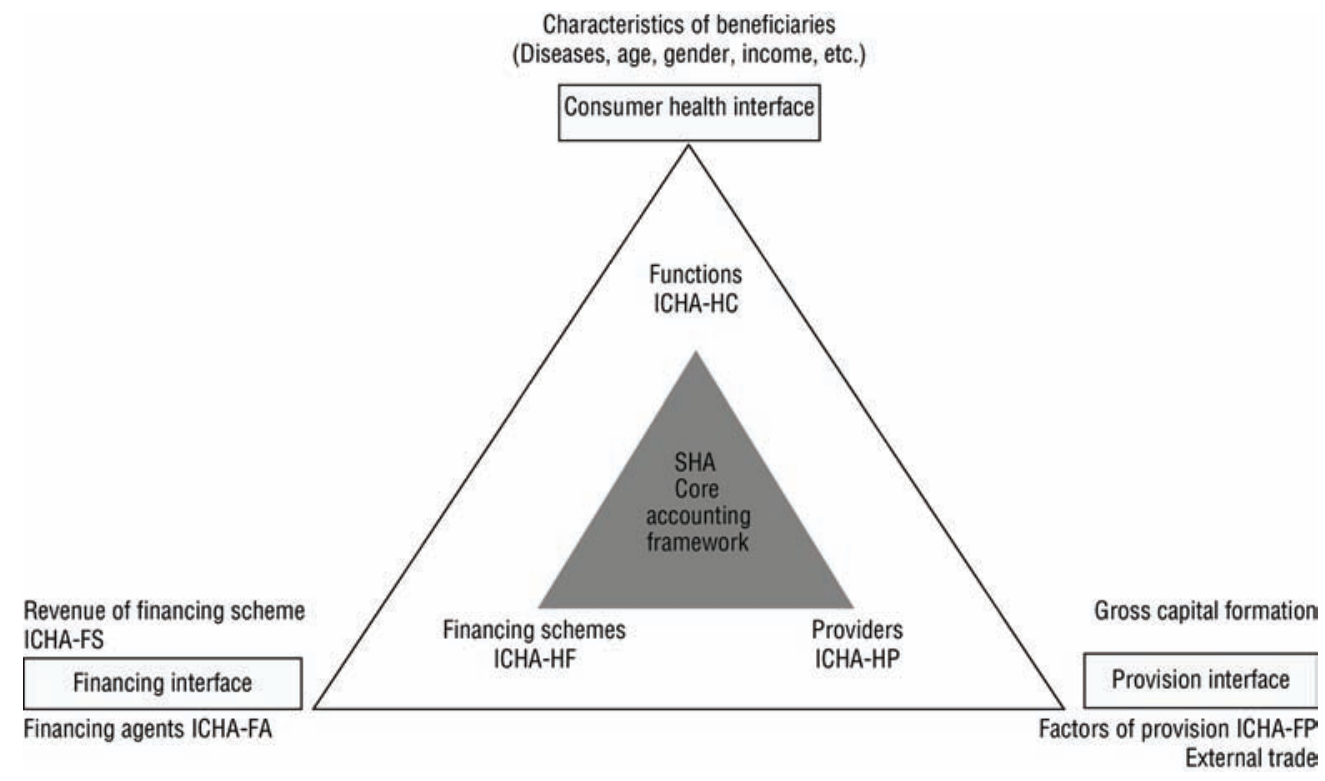

Source: IHAT for SHA 2011.

The consumer health interface related to the core accounts is of a different nature to the other two interfaces. The aim of developing the consumer health interface to ICHA-HC under the SHA is to provide more detailed information on health care expenditure in relation to the uses and beneficiaries of the health care system. The distribution of health care expenditure by patient characteristics (e.g. age, gender, socioeconomic status or diseases/condition of beneficiaries), population morbidity (incidence or prevalence of diseases), and its burden both in monetary and non-monetary terms can give health care policy makers important information for re-designing health care priorities and reallocating available resources. While information derived from the consumer health interface can be used as an input to priority setting, the information from either the financing or the provision interfaces gives insights into the type and level of resources available. Accordingly, information on the revenues of the financing schemes, on health care exports and imports (external trade), on the cost of inputs used in health care provision or, importantly, information on capital formation, education, training, and research in the health sector, can provide further support to decisions on changes in the allocation of health care sector resources.

\section{Criteria in boundary setting}

Countries differ in financing and organisation of their health care system and in the range of goods and services consumed. From an international perspective, developing a common boundary of functionally defined health care systems means setting the limits on the scope of health care activities to be included in order to improve the comparability of cross-country data. Four main criteria are set out to determine whether an activity should be included within the core expenditure account of the SHA; these are presented below, in order of importance:

- The primary intent of the activity is to improve, maintain or prevent the deterioration of the health status of individuals, groups of the population or the population as a whole as well as to mitigate the consequences of ill health; 
- Qualified medical or health care knowledge and skills are needed in carrying out this function, or it can be executed under the supervision of those with such knowledge, or the function is governance and health system administration and its financing;

- The consumption is for the final use of health care goods and services of residents;

- And there is a transaction of health care services or goods.

The main criterion to include or exclude certain activities relates to their role in enhancing health status, diminishing ill-health, or preventing the deterioration of the health of individuals and/or the population as a whole. Here, by convention, the administration and governance of the health care system is also included. Although direct contact with the patient is not explicitly introduced as a criterion, it is obvious that for cure and treatment as well as in personal prevention direct contact is a necessary prerequisite. In the case of collective prevention activities, both direct and indirect contacts with the target group of population are possible. Another criterion is the amount of medical, nursing or health knowledge needed to perform the activities, or the degree to which medical, paramedical or nursing professionals are involved in the provision process. The last two criteria imply that it is also important to distinguish whether the health care goods and services subject to the transactions are consumed by patients, or utilised by the target population groups, or further transformed and used up within the production process as intermediate consumption, ${ }^{4}$ or increase the stocks of goods as capital formation. All four criteria are further discussed in the next section.

Consequently, neither the reimbursement of the cost of health care goods and services nor information and data historically collected by a country's statistical system are a key criterion for inclusion or exclusion. In reality, this means that certain goods and services recorded by a particular country under health care might not be included for the purpose of international data collection, and that some goods and services not recorded might be included. Furthermore, the specific health care transactions requested under the SHA may not always be in agreement with the available data or the way that the statistical system is designed at a national level. Both over- and under-estimation of the aggregates may occur, as well as a certain level of ambiguity concerning the transactions, due to a lack of detailed data, which might be difficult to prevent. From a data comparability point of view, any departures from SHA should be minimised as far as possible, and well documented.

\section{The boundary of the current health care expenditure account}

\section{The consumption frame of health care goods and services}

The boundaries of the current health expenditure account are established by the purposes of the consumption of the health care goods and services included. These purposes are discussed in detail in Chapter 5 "Classification of health care functions" (ICHA-HC). Here, however it is essential to clarify certain aspects of the general structure, which can provide a bridge across accounting concepts and definitions, as described in Chapter 3, and the health care boundary criteria set up in operational terms, including specific rules on how to handle borderline issues.

\section{Boundary criteria in operational terms}

In accordance with the purposes, health care comprises health care goods and services provided directly to individual persons as well as collective health care services. The latter covers health care prevention programmes as well as administration of both the health 
care system itself and its financing. The prevention tasks and collective health care services commonly include epidemiological surveillance and other measures of health promotion and disease prevention, including the establishment and enforcement of good practices or standards in public health, as well as the provision of health care prevention programmes and their administration. Governance and administration of the health care system comprises activities related to planning, management and regulation of the health care sector as a whole in order to ensure its effectiveness, including tasks related to collecting, pooling and distributing funds by government units and/or health insurance, as well as other financing agents (see Chapter 5).

Health care goods and services provided to and consumed by individuals comprise the majority of transactions recorded in the core accounting framework and grouped under the specific functions, such as curative and rehabilitative services, long-term care (health), preventive immunisation or screening, or pharmaceuticals and other medical goods. The ICHA-HC functional classification also distinguishes on the second-digit level between different types of settings, so-called modes of provision, by which the services are provided: inpatient care, day-care, outpatient care and home care. One should note that health care services offered at the workplace or school, although provided in specific settings, are also included here, as the purpose is health improvement, regardless of the provider settings or facilities and their regulatory status. Among health care goods and services consumed by individuals, occupational health services require particular attention, because these services are often provided by specialists of occupational medicine within an industry setting. ${ }^{5}$ When occupational medical services for employees are outsourced (contracted out to offices of medical specialists), caution in data compilation is recommended to avoid the potential for double-counting.

Regarding the level of medical knowledge and skills that are needed to carry out health care activities, SHA 2011 refers to the International Standard Classification of Occupations (ISCO). This classification recognises medical occupations by classifying them under health professionals and associate professionals, including medical and paramedical, nursing and other health professionals based on both the tasks and duties undertaken as well as educational and skill type criteria. Therefore it is recommended that the ISCO be used as background information on the set of medical occupations characterised by the application of qualified medical knowledge and skills. In operational terms, the reference is to ISCO categories 2200 and 3200, excluding veterinary occupations - see Annex C. Activities related to Traditional, Complementary and Alternative Medicine (TCAM) goods and services are in general included - although to be dealt with individually on a country by country basis - on the scope of tasks provided by both TCAM professionals and associate professionals as classified in ISCO (groups 2230 and 3230). ${ }^{6}$

Regarding the notion of activities to be carried out under the supervision of those with qualified medical or health care knowledge and skills, application of this criterion will generally be left to the discretion of the countries, as national arrangements of health care delivery can differ significantly. Nevertheless, the common understanding is that a minimum level of such supervision should consist of basic introductory training and occasional visits or consultations by the qualified medical professional (a supervisor) in order to ensure the services are performed by the care givers satisfactorily.

The current health care expenditure account of SHA focuses on final consumption and not on intermediate consumption of services and goods. In other words, SHA does not aim 
to account for health care goods and services provided as intermediate output to other providers. This is the case, for example, when one hospital provides or carries out a laboratory test for another hospital. In the case of inpatient and day-care services, health expenditure should comprise all medical services and goods received during the episode of care, regardless of the provider or the payer. The provision of a laboratory test by Hospital A to Hospital B leads to expenses for B and revenues for A. However, the laboratory tests are part of the treatment processes offered by Hospital B. Therefore, the provision of laboratory tests by Hospital A is counted, but as a part of the output and billing of Hospital B, and as such is considered in SHA as final consumption of health care goods and services. In this example, the additional compilation of the laboratory test of Hospital A would lead to double-counting from a consumption point of view and is therefore not shown separately. In fact, it is essential that total expenditures for hospital care or any other providers are reconciled for interflows among providers. Intermediate consumption is not limited to goods and services that are delivered by health care providers to other providers, but also includes goods and services that might be delivered by units of the rest of the economy, such as electricity and water.

SHA focuses on the consumption of health care goods and services by the resident population irrespective of where this takes place. This implies the inclusion of imports (from non-resident providers) and the exclusion of exports (health care goods and services provided to non-residents). In practice, when business or establishment surveys of resident providers are the starting point for the construction of the SHA, this may result in the inclusion of exports of health care (delivered to non-residents but provided by resident units) and the neglect of imports of health care from non-resident providers. As the extent of cross-border trade becomes more important, other sources of information, such as travel surveys or insurance claims for reimbursement of services bought abroad, may be considered as an estimating factor (see Chapter 12 for further boundary considerations related to cross-border trade).

Another aspect to be considered in the consumption of health care is the non-observed economy, i.e. unrecorded, illegal or informal activities that are not always captured or reported in regular statistical sources. The reason for this may be that the activity is informal, and thus escapes the attention of official surveys; it may be that the producer is anxious to conceal a legal activity, or it may be that the activity itself is illegal. In some countries the consumption of health care goods and services is often related to informal payments, so-called "envelope payments" or "under-the-table payments". Whether these payments relate to normal or additional services provided to patients or represent a patient's additional gratitude to the physician, these extra unrecorded payments increase the incomes of health care providers on one side and add to the financial burdens of the consumer on the other side. The non-observed health economy may account for a significant part of the health care system for some countries. It is therefore particularly important to try to make estimates of the total consumption of health care, even if it cannot always be separately identified as such. ${ }^{7}$

SHA refers to valued transactions, i.e. transactions under which payments are made to providers in exchange for health care goods and services received by consumers. In other words, the flow of health care goods and services is accompanied by a flow of financial or other means. Usually, these payments go to health care providers and are made directly by patients or indirectly by other actors in the health care system (for example, government or health insurance) on behalf of individuals or groups of the population. However the 
recipient of these payments may not necessarily be a typical health care provider like a hospital or physician but a household which, under certain circumstances, may provide some health care services to other members of the family. These circumstances refer to the provision of health care services at home (home health care) that are usually made under supervision of medical or paramedical professionals or on the condition that the family member who provides them possesses certain medical knowledge that could be used for this purpose.

This requires that SHA considers households not only as a financing agent that pays for health care goods and services purchased or consumed, but also as a specific health care provider that can deliver services under certain circumstances. ${ }^{8}$ The scope of health or health care-related services provided at home by family members often is a mixture of health and social care services. This leads to the problem of how to split the health care component from the social one when classifying these activities under SHA. For the health care component, SHA recommends taking into account nursing care activities, which are often provided in combination with personal care services, notably assistance with activities of daily living (ADL). ${ }^{9}$ If these activities are paid, for instance, via "nursing allowances" or other transfers granted for the care of household members due to their health problems, then they are to be included in the current health care expenditure account. The interpretation here is that benefits granted for care to members of households are included if they are paid. It is also assumed that behind the decision to grant benefits, there is usually a preceding medical examination and periodic supplementary examinations to evaluate whether or not the person is still eligible for the benefits. Other benefits in cash, such as benefits for sickness leave or maternity leave or pensions for disabilities or work accidents, are granted for the purpose of income maintenance and are therefore excluded from the core accounting framework.

Consumption is valued at purchasers' prices including any (non-deductible) value added tax (VAT). This means that the value of medical goods and services is based on what purchasers pay. ${ }^{10}$ Even if medical services and pharmaceuticals are provided free of charge, it is necessary to estimate the values that are equivalent to market prices. Often, health care services and medical goods are provided free of charge or at user charges which are below prices "that are economically significant". ${ }^{11}$ When reliable market prices cannot be obtained, a second best procedure is to value the output to be equal to the sum of its cost of provision: that is, as the sum of selected inputs, including transport charges and trade margins. More detailed information about the type of factors of provision is provided in Chapter 9.

Many prices of health care goods and services are the result of complex institutional pricing arrangements in which the prices contracted, for example, by health insurance, may not include the cost of capital services, which can be paid separately by government or other financing agents. One of the costs of providers' services is the consumption of fixed capital (CFC), or what is called depreciation in business accounting, ${ }^{12}$ for example for hospital buildings, medical equipment or expired pharmaceuticals that can no longer be prescribed. This is the value loss of the capital assets used up in the process of delivering health care goods and services during the current period, resulting from physical deterioration, normal obsolescence or damage. It measures the decline in the usefulness of a fixed asset for purposes of health care provision. Within the core accounting framework, CFC should always be included in the price of health care goods and services. As discussed in Chapter 3, in some cases purchases of health care goods and services by financing 
schemes (or agents) do not cover the cost of capital, so the respective amount has to be estimated.

\section{Borderline cases}

SHA consumption frame draws the borderline irrespective of where and by whom (although with reference to the second criteria) the activities are provided and how they are financed. The functional classification of health care sets the borderline according to purpose. In some cases, such as with cosmetic surgery, the transportation of patients, home help services, sunglasses or condoms, it might not be clear whether or not to classify these services and goods under the current health expenditure account. In general, borderline cases refer to specific goods and services that are situated on the boundaries of health care and health care-related or non-health-care products. ${ }^{13}$ As it is not always easy to make a distinction between these, as a rule of thumb the four criteria for health care boundary setting should be verified at the outset, followed by specific rules on how to handle borderline cases. In many cases, a reference to medical recommendations can serve as additional guidance (see Table 4.1 for further details). Here, three particular areas of borderline cases are briefly discussed:

- Multi-sectoral issues;

- Wellbeing;

- Social care.

A large group of borderline cases relate to multi-sectoral issues such as road safety, intentional injuries or improving health equity by reducing poverty. The main criterion for the decision to include or exclude these activities in SHA is whether the primary purpose of these activities is health and whether an application of medical knowledge and technology is involved. For example, road safety measures are quite important to reducing road injuries; however, the primary purpose is public safety and movement from one place to another, rather than health. Therefore, it would be misleading to include the cost of road construction, road signs and crash barriers in the accounts in addition to the cost of medical treatment of injured persons. Similarly, safety tests for cars, seat belts or policy activities geared towards road safety are considered outside the boundary of health care goods and services. However, preventive measures related to the above activities can be recorded as an additional layer to the consumption frame, in particular as health carerelated activities proposed in SHA 2011.

Another group of borderline cases concerns well-being services, such as those provided in spas and wellness centres. The perception of health services is evolutionary, intercultural and social (Petrera and Vicente, 2008). The understanding of the relationship between welfare, well-being, lifestyle and health status as well as the scrutiny of the effectiveness of health care goods and services might vary between countries. The current health care expenditure accounts aim to measure neither the impact on welfare nor the effectiveness of health care services. Goods and services directed primarily to well-being, such as fitness training or specific diets, might well have a health impact but are excluded from the consumption frame unless they are part of activities recommended medically and thus conform to the four health care boundary criteria (for details, see Chapter 5). ${ }^{14}$ In the case of cosmetic surgery or dental work for aesthetic purposes (e.g. teeth whitening), this should be excluded (when it can be separately identified); despite the medical 
knowledge, technology and personnel involved in its provision, it does not meet the first criterion. ${ }^{15}$

The aim of social care is to provide services and support, by formal and informal caregivers, to individuals who, for reasons of disability, illness or other dependency, need help to live as normal a life as possible, either within a residential care setting or in their own home. Social care covers a wide range of services, including professional advice and support, accommodation, various types of assistance in carrying out daily tasks, home visits, home help services, provision of meals, special equipment, house adaptation for disabled persons as well as assessment and care management services. Often local authorities are responsible for assessing the care needs of their populations as well as the planning and provision of services. In reality, there may be a mixed economy of social care provision (by public, non-profit and for-profit providers), various mechanisms for its financing (direct payments, reimbursements, benefits in cash, etc.) and different arrangements for its delivery (pure social components or a mixture with various levels of medical care). The latter mix of services often makes it difficult to separate between health components and social components with services related to help with activities of daily living (ADL) and instrumental activities of daily living (IADL). ${ }^{16}$ An assessment of care needs frequently involves input from medical professionals and often is in response to an underlying medical condition or disability. Therefore, long-term care (health) in SHA 2011 includes personal "body help" type services (e.g. help with ADL) under health expenditure, while "assistance or home help" type services (e.g. help with IADL) should be separately counted as long-term care (social) outside the core health care boundary and recorded under the health care-related category (HCR.1). If, however, long-term care (social) services are also delivered as part of a service package in which a medical or nursing care component dominates, then the expenditure for these should also be included under health care, and vice versa. ${ }^{17}$ This aside, the health accounting framework leaves open the possibility to identify total long-term care spending, that is, the aggregate of the health and social components, which may be of greater policy relevance.

\section{Layers of the consumption frame}

The layers of the consumption frame can serve different purposes. In SHA 1.0, the "health care-related functions" were introduced as additional layers to the functional classification, encompassing areas that overlap with the health domain on the one hand but go beyond the health care boundary on the other hand. Seven health-related functions were proposed: 1) capital formation of health care provider institutions; 2) education and training of health personnel; 3) research and development in health; 4) food, hygiene and drinking water control; 5) environmental health; 6) administration and provision of social services in kind to assist living with disease and impairment; 7) administration and provision of health-related cash-benefits. In the joint OECD, ESTAT and WHO SHA data collection, the "memorandum items" were introduced with reference to aggregates on specific expenditure categories such as totals of pharmaceuticals and of ancillary services (in both cases including inpatient and other modes of provision) that cannot be directly obtained from the functional classification categories. All these functions and items are of interest, as they constitute relevant parameters for health policy.

As far as the different layers are concerned, SHA 2011 recognises the importance of the purposes behind both the "health care-related functions" and the "reporting items" layers. However, it recommends that they refer to the consumption of health care goods and 
services following one of the main criteria under this frame. Accordingly, certain modifications and additions to SHA 1.0 concept are made in the functional classification in Chapter 5. In general:

- Capital formation is considered separately due to the complexity of this subject, the experiences hitherto of international data collection as well as the different nature of spending on capital formation compared to consumption spending on health care. Chapter 11 of SHA 2011 proposes a set of guidelines for estimating capital formation with a more comprehensive approach than in SHA 1.0. In addition, it addresses both the education and training of human resources as well as research and development as memorandum items.

- From a wide range of multi-sectoral health care-related activities, SHA 2011 recommends distinguishing two groups of activities, i.e. i) the social part of long-term care, and ii) activities of prevention linked with multi-sectoral health care that may involve a public safety interest in a wide sense.

- As reporting items for the totals of specific expenditure categories, it is proposed that three groups be captured under the functional classification: i) pharmaceuticals (including that of inpatient care), ii) TCAM and iii) prevention. The latter classifies expenditure according to SHA 1.0 subcategories of prevention and public health services.

\section{The boundaries of the additional expenditure accounts of SHA}

\section{Dimensions of extension}

Depending on the additional activities considered, the boundaries of the extended health accounts can differ from current health expenditure captured under the core accounting framework. There are three main interfaces, offering additional classifications and further breakdowns of expenditure, which link the core health expenditure account to a broader set of statistical areas (see Figure 4.1):

- The consumer health interface;

- The provision interface;

- The financing interface.

The derived additional expenditure accounts of SHA give the opportunity to develop all these areas in more detail. In the following, only a general overview of the interfaces and their relation to the boundary of the core accounting framework is presented. Some of them are discussed further in Part 2 and in the annexes.

\section{Consumer health interface}

The consumer health interface is of particular interest to the study of the relationship between the consumption of health care goods and services and the associated health enhancement of the population. Although health is only partly determined by the consumption of health care, the breakdown of health care expenditures by various characteristics of beneficiaries (see Chapter 10) helps to improve the understanding of the observed distribution in overall health spending. Health differences among individuals and population groups are apparent along many dimensions, including age, gender, socioeconomic status (SES) and geographic area. Age and gender are demographic characteristics of beneficiaries that form an intrinsic epidemiological part of identifying and measuring the utilisation of health care goods and services by type of disease. 
Some components of the consumer health interface are closely connected to the social area. Organising equal access to health must take into account the diversity of people's social, cultural and ethnic backgrounds. ${ }^{18}$ Identifying and measuring the burden of health care financing in different social groups of the population adds to the understanding of both consumption and financing patterns. It also helps to improve the consistency of health accounts. Health expenditures are quite unevenly distributed among population groups. Socio-economic variables may determine not only health, but also, in public financing schemes, any exemptions from co-payments. "Catastrophic" health expenditures and out-of-pocket expenditures that low-income households face are therefore of particular interest for health accounts and add valuable information to the knowledge about both the demand for health care and its accessibility (O'Donnell et al., 2008).

Employing consistent methodology and data sources can ensure that expenditures for various diseases can be compared and that the sum of expenditures for all diseases equals the estimate of current health expenditure. SHA offers the possibility to develop consistent expenditure by disease accounts. In practice, this means mainly a top-down approach to the allocation of health expenditures by specific health status classifications based on the International Classification of Diseases (ICD), keeping the boundary of the current health care expenditure account. ${ }^{19}$ The cost of disease is different from the total cost faced by the patient. One reason is the inclusion of indirect costs. Indirect costs in the estimation of the so-called Cost Of Illness $\left(\mathrm{COI}^{20}\right)$, or productivity loss, measures the loss in earnings as a result of death, illness or time spent undergoing treatment for the population as a whole. The loss of earnings comprises both those of the patient and those of family members caring for the patient. Usually indirect costs are larger than health-related cash benefits, because these benefits do not fully replace the loss of income. The cost framework might also include intangible costs, e.g. costs of pain, suffering, anxiety, grief and loss of leisure time, for which a monetary value is assigned.

Current health expenditures can be considered as the product of the annual prevalence of patients receiving health care goods and services and the average value of these health care goods and services. The ability to link monetary with non-monetary data gives opportunities to gain information about utilisation, incidence and prevalence that is essential for measuring unit costs of health care services. Unit costs may be important for developing health price indices (see Chapter 13). In addition, information about unit costs could be used for checking the consistency of the accounts.

\section{Provision interface}

The provision interface offers links to additional dimensions and accounts, such as the classification of factors for health care provision (see Chapter 9) or the capital formation account (see Chapter 11). The focus switches here from consumption to the provision approach. In the current health expenditure account, the total of provision equals the total of consumption and the total of health care financing. It is important to distinguish between "provision" as the output of health care products and the "production" of providers as a process that relate inputs to outputs. Health care provision for final consumption differs from the production of health care providers by the external trade in health care goods and services, the production of non-health products, and the production of health care goods and services used as intermediate consumption. From an economic perspective, the total value of the production of the health care system and the related value added are of interest. Such a broader economic perspective is taken in full health 
care satellite accounts that compile both the supply and the use of health care goods and services.

The factors of provision (FP) are the factor inputs used by providers to produce the goods and services consumed or the activities conducted in the system. The boundary for measuring factors of health care provision is derived from the outputs of health care providers. Usually this differs from the boundary of health care consumption of the core health expenditure account. One particular issue concerning the factor of provision account is that the factor costs of health care providers also include items related to nonhealth products and exports. Chapter 9 recommends taking account of these in order to preserve the current health expenditure boundary. The extension of the core account of SHA to FP might be of interest for various reasons, e.g. the cost of the various components driving the expenditure increase varies according to the organisation of purchase and provision and the strength of health professionals in the health care market. In many highincome countries, human health resource costs are the most important group of variables among the factors of the health care provision account, including wages and salaries as well as social dues to be paid on earnings. By contrast, in lower-income countries, the cost of medicines can play a significant role. Furthermore, the compilation of intermediate consumption in the factors of provision account of SHA 2011 allows the measurement of the intermediate use of health care goods and services by health care providers and allows for checking interflows among providers. ${ }^{21}$

The generation of resources by investment in key inputs and technologies (capital, human and knowledge) determine the capacities of the health care system. Information and communication technologies as well as medical equipment are nowadays integrated in almost all health care provision processes and give opportunities for further improvements. Capital formation is a crucial factor in the provision of health care goods and services by health care providers and in the enhancement of their quality. Capital formation deals with changes in the equipment, buildings and instruments used by providers, including amongst other things the acquisition and application of new medical technology. Gross capital formation is measured in the capital account by the sum of three components: gross fixed capital formation plus changes in inventories plus acquisitions less disposals of valuables. A human capital account would record expenditures for the formation of human capital in health care as well as the human resources in health care. Human capital and health knowledge are, like physical capital, crucial factors in the provision of health care goods and services by health care providers and in the enhancement of their quality. Human capital within the health care system consists of the stock of knowledge, skills and experience embodied in the labour force, including all types of skills, ranging from medical to IT, cleaning and management, which is taken as a proxy for human capital. SHA 1.0 recognised the importance of the labour force and proposed the measurement of human resources in health care in a stock-flow approach and expenditures for activities involving education and training (SHA1.0: HC.R.2). Furthermore, the amount of resources devoted to innovation, science and inventions is measured in the form of expenditures for research and development in health (SHA1.0: HC.R.3). Both types of expenditures are not for current final consumption, but influence final consumption in the future. Like capital formation, they are invested by health care providers as inputs into the future capacities of the health care system (see Chapter 11, memorandum items). 


\section{Financing interface ${ }^{22}$}

The financing interface offers the possibility to expand the accounting of health care financing to a detailed analysis of the revenue side of financing schemes (see Chapter 8) and their linkages with the institutional sectors of the SNA. Information about health care financing is limited in the core expenditure account to answering the questions: "where does the money go to?" and "which types of different services are financed?" (HFxHPxHC). The financing interface aims to provide a more comprehensive picture about financing flows in health care, by providing answers to the questions: "where does the money come from?" and "what instruments are used for fund raising?". Two types of information can be gained from the revenues of schemes account. On the one hand, it may focus on tracing back the funds that are at the disposal of financing schemes, i.e. the flows from the institutional units of the economy (general government, non-financial corporations, financial corporations, households and NPISH) and from the rest of the world to the financing schemes. On the other hand, of particular interest might be information on contribution mechanisms, i.e. the way the health care funds were collected (government contributions, health insurance premiums, grants, transfers, etc.) in relation to issues of the fiscal stability, sustainability and equity of health care financing.

Identifying financing agents, which are the institutional units, and the types of revenues for each financing scheme, allows for a better interpretation of public and private funding in the health care sector. For example, "households", as an institutional sector, belongs to the private sector, so household out-of pocket direct payments for purchasing health care goods and services are considered as private funding. However, social health insurance contributions paid by households via health insurance premiums are considered as elements of public funding, in contrast to the voluntary health insurance premiums paid by households, which are considered as elements of private funding. In addition, the revenues of financing schemes account can provide information about discrepancies between the receipts and the expenses of financing schemes. Revenues and expenditures of financing agents/schemes may not be balanced. The total expenditure in HCxHF and the HPxHF tables does not necessarily equal the total revenue in the HFxFS table. ${ }^{23}$ The differences show the surplus or deficit of the particular health care financing schemes. A related issue concerns intergenerational imbalances in the financing system. Contributions (private and public) and premiums paid by one generation are by definition not always equal to the payments necessary for service delivery for that generation (Auerbach et al., 1994).

To sum up, the extension to the revenues of financing schemes does not change the consumption boundary considered in the core health care expenditure account, but adds distributive transactions to the health accounts at the financing interface. Imbalances between the revenues and expenditures of schemes might be accumulated over several years. These deficits or surpluses change the financial position of the financing schemes, i.e. their financial assets and liabilities. SHA 2011 does not provide guidelines for the recording of financial assets and liabilities. If accountants are interested in expanding the financial accounts further, they should follow the rules laid down by the Government Finance Statistics Manual (GFSM, IMF, 2001) and SNA. 


\section{Table 4.1. Selected borderline cases of the SHA core accounting framework}

\begin{tabular}{|c|c|c|c|c|c|}
\hline \multirow[t]{2}{*}{ Borderline activity } & \multicolumn{4}{|c|}{ Criteria in boundary settings } & \multirow[t]{2}{*}{ Main arguments and recommendations to include/exclude from health care function } \\
\hline & 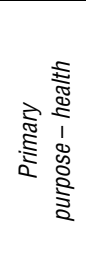 & 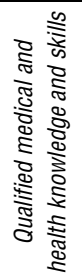 & 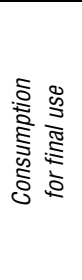 & 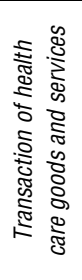 & \\
\hline $\begin{array}{l}\text { Cosmetic surgery for reconstruction } \\
\text { of traumatic damage }\end{array}$ & yes & yes & yes & yes & Included. \\
\hline Other cosmetic or plastic surgery & $?$ & yes & yes & yes & $\begin{array}{l}\text { Often no health purpose; performed by medical (surgeons) professionals; using } \\
\text { medical technology; presence of transitions. Pure aesthetic services should be } \\
\text { excluded. }\end{array}$ \\
\hline In-vitro or artificial fertilisation & yes & yes & yes & yes & Included. \\
\hline Autopsies & $?$ & yes & $?$ & $?$ & $\begin{array}{l}\text { Might be no health purpose (e.g. criminal evidence), as well as not for final } \\
\text { consumption. Included under condition of collective health purpose and final } \\
\text { consumption. }\end{array}$ \\
\hline Forensic medicine & yes & yes & yes & $?$ & $\begin{array}{l}\text { Forensics makes large use of health knowledge and technology (incl. psychology); } \\
\text { autopsies and forensics are linked services linked. Included for personal and collective } \\
\text { health purpose and final consumption; excluded as intermediate consumption. }\end{array}$ \\
\hline Telemedicine & yes & yes & yes & $?$ & $\begin{array}{l}\text { Performed using medical and paramedical knowledge and technologies. Included for } \\
\text { personal and collective health purpose and final consumption; excluded as intermediate } \\
\text { consumption. }\end{array}$ \\
\hline $\begin{array}{l}\text { Psychological therapy/psychotherapy } \\
\text { related to mental or physical abuse }\end{array}$ & yes & yes & yes & yes & Included. \\
\hline Chiropractors' services & yes & yes & yes & yes & $\begin{array}{l}\text { Included if medically prescribed and provided by health professionals } \\
\text { (see ISCO 08). }\end{array}$ \\
\hline $\begin{array}{l}\text { Alternative healers/ alternative } \\
\text { medicine }\end{array}$ & yes & $?$ & yes & yes & $\begin{array}{l}\text { Included if follows the rules for TCAM ISCO } 08 \text { ( } 2230 \text { Traditional and complementary } \\
\text { medicine professionals, and } 3230 \text { Traditional and complementary medicine associate } \\
\text { professionals). }\end{array}$ \\
\hline Acupuncture & yes & yes & yes & yes & $\begin{array}{l}\text { Included if medically prescribed and provided by health professionals (ISCO 08: see } \\
\text { above). }\end{array}$ \\
\hline $\begin{array}{l}\text { Services provided by balneology } \\
\text { institute }\end{array}$ & yes/no & yes/no & yes & yes & $\begin{array}{l}\text { The very large spectrum of such services often provided by non-health professionals; } \\
\text { seldom prescribed as part of a medical treatment. Included, if curative, rehabilitative, or } \\
\text { prevention function, and if provided by health professionals. Excluded as sports, } \\
\text { wellness or leisure purposes. }\end{array}$ \\
\hline Long-term care & yes & yes & yes & yes & $\begin{array}{l}\text { Included: nursing long-term care and personal care with a health purpose, contrary to } \\
\text { social care. }\end{array}$ \\
\hline $\begin{array}{l}\text { Summer camp for disabled people } \\
\text { and/or for whole family with disabled } \\
\text { children providers }\end{array}$ & $?$ & $?$ & yes & yes & $\begin{array}{l}\text { Pros: the main purpose of such services may be support to activities of daily living } \\
\text { (ADL); could have a rehabilitative component. Cons: included in health-related } \\
\text { functions; activities go beyond daily living. Excluded if the social component is main } \\
\text { purpose (only medical/health components are included). }\end{array}$ \\
\hline $\begin{array}{l}\text { Orphanages (orphans and disable } \\
\text { children) home for children }\end{array}$ & $?$ & $?$ & yes & yes & $\begin{array}{l}\text { Generally considered as institutions of social care. Excluded if social component is main } \\
\text { purpose (only medical/health components are included). }\end{array}$ \\
\hline Crèches for $0-3$ & $?$ & no & yes & yes & $\begin{array}{l}\text { Generally considered as institutions of social care related to the purpose of supporting } \\
\text { women's participation in labour market. Excluded. }\end{array}$ \\
\hline $\begin{array}{l}\text { Housing adaptation such as automatic } \\
\text { staircase lifts }\end{array}$ & $?$ & no & no & no & $\begin{array}{l}\text { There is a large spectrum of such technical devices, which are generally not bound to } \\
\text { health services or provided by health professionals. It is investment rather than care. It } \\
\text { doesn't improve health but standard of living. Excluded. }\end{array}$ \\
\hline $\begin{array}{l}\text { Recreational services (in mental } \\
\text { health or residential care settings) }\end{array}$ & $?$ & no & yes & yes & Excluded. Only medical/health components are included. \\
\hline Massages & $?$ & $?$ & yes & yes & $\begin{array}{l}\text { Included, if provided by health professionals and medically prescribed (see ISCO 08: } \\
2264 \text { Physiotherapist and } 3255 \text { Massage therapist). Excluded are Beauticians and } \\
\text { related workers (ISC008: } 5142 \text { ). }\end{array}$ \\
\hline Fitness activities & $?$ & $?$ & yes & yes & Excluded unless these activities are under medical recommendation. \\
\hline Nutritional products & $?$ & $?$ & yes & yes & $\begin{array}{l}\text { Pros: contribute to improvement of health, products sold in pharmacies and/or } \\
\text { prescribed by doctors. Cons: also sold in supermarkets; Included in case of health } \\
\text { purpose and under the supervision of health professionals. }\end{array}$ \\
\hline Vitamins and minerals & yes & $?$ & yes & yes & Included in HC.5.1.2 Over-the-counter drugs (ОTC) even if provided by supermarkets. \\
\hline
\end{tabular}




\section{Table 4.1. Selected borderline cases} of the SHA core accounting framework (cont.)

\begin{tabular}{|c|c|c|c|c|c|}
\hline \multirow[t]{2}{*}{ Borderline activity } & \multicolumn{4}{|c|}{ Criteria in boundary settings } & \multirow[t]{2}{*}{ Main arguments and recommendations to include/exclude from health care function } \\
\hline & 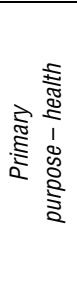 & 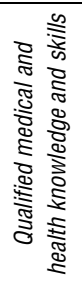 & 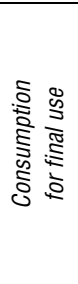 & 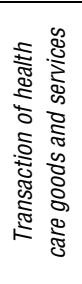 & \\
\hline Maternal and child health & yes & yes & yes & yes & $\begin{array}{l}\text { Both prevention and cure elements with a wide range of health care services (e.g. } \\
\text { genetic counselling and prevention of specific congenital abnormalities, etc.) Included. }\end{array}$ \\
\hline Occupational health care & yes & yes & yes & yes & Included as final consumption in SHA (in SNA intermediate consumption). \\
\hline Blood pressure instruments & yes & yes & yes & yes & $\begin{array}{l}\text { Included under HC.5.2.9 for Households. If intermediate output for professionals then } \\
\text { to be excluded. }\end{array}$ \\
\hline Sunglasses & $?$ & $?$ & yes & yes & $\begin{array}{l}\text { Included but on a restrictive basis, only when medically prescribed or advised with a } \\
\text { clear health purpose distributed by health professions (ISCO 08). Exclude fashion } \\
\text { articles for pure aesthetic purposes. }\end{array}$ \\
\hline Sun cream & $?$ & $?$ & yes & yes & Included but on a restrictive basis, only medically prescribed. \\
\hline $\begin{array}{l}\text { Condoms and other mechanical } \\
\text { contraceptive devices }\end{array}$ & $?$ & $?$ & yes & yes & Included in HC.5.1.3 Other medical non-durable goods. \\
\hline $\begin{array}{l}\text { Patient transport to and from facilities } \\
\text { for the purpose of receiving medical } \\
\text { care, by taxi or other conventional } \\
\text { vehicles use }\end{array}$ & yes & no & yes & yes & $\begin{array}{l}\text { Pros: the transportation service is needed because of the health status or to get a health } \\
\text { provision. Cons: the service is generally not provided by health professionals; when } \\
\text { provided in a health institution, this expenditure is already included in the main product } \\
\text { (intermediate consumption, not final use). Included if provided under medical } \\
\text { recommendation }\end{array}$ \\
\hline $\begin{array}{l}\text { Ambulance services which do not } \\
\text { result in the transport of patients }\end{array}$ & yes & yes & no & yes & Intermediate consumption. Excluded. \\
\hline $\begin{array}{l}\text { Services of patient-supporting } \\
\text { organisations in relation with diseases }\end{array}$ & yes & $?$ & yes & $?$ & $\begin{array}{l}\text { Included if services (consultation) directly related to heath purpose (except legal } \\
\text { services). }\end{array}$ \\
\hline Orthopaedic shoes & yes & $?$ & yes & yes & $\begin{array}{l}\text { Included if prescribed by a licensed medical practitioner and provided by orthopaedic } \\
\text { technicians. }\end{array}$ \\
\hline Other medical goods industry & $?$ & $?$ & $?$ & $?$ & $\begin{array}{l}\text { Usually intermediate products. Excluded if these goods are not directly provided to the } \\
\text { patient. }\end{array}$ \\
\hline $\begin{array}{l}\text { Health policy formulation outside } \\
\text { central government/consultancy }\end{array}$ & yes & $?$ & no & yes & $\begin{array}{l}\text { In health programmes and donor programmes consultancy can be offered as part of the } \\
\text { package. Usually excluded because kept as intermediate products. }\end{array}$ \\
\hline Activities of organ banks & yes & yes & $?$ & yes & Not included as it is intermediate consumption of other health providers. \\
\hline Export of health services & yes & yes & yes & $?$ & Transactions not related to resident population. Excluded. \\
\hline $\begin{array}{l}\text { Health care production for own final } \\
\text { use }\end{array}$ & yes & $?$ & yes & $?$ & $\begin{array}{l}\text { In SHA (contrary to SNA) is treated as replacement of professional health care under } \\
\text { certain conditions (e.g. nursing allowance granted to households for care of one family } \\
\text { member, usually case of home LTC). Included if payment involved. }\end{array}$ \\
\hline $\begin{array}{l}\text { Medical association, nurses unions } \\
\text { and the like (umbrella organisations } \\
\text { for professionals) }\end{array}$ & $?$ & $?$ & $?$ & $?$ & Not a health activity toward patient. Excluded (intermediate services). \\
\hline $\begin{array}{l}\text { Refresher training (courses to be } \\
\text { followed by professionals on an } \\
\text { obligatory or voluntary basis) }\end{array}$ & no & yes & no & $?$ & Excluded (intermediate consumption/input factor). \\
\hline Biochemical engineering & $?$ & $?$ & $?$ & $?$ & $\begin{array}{l}\text { Pros: performed for public health institutions or the pharmaceutical industry. Cons: } \\
\text { these products are integrated as intermediate consumption in health care goods and } \\
\text { services. Excluded. }\end{array}$ \\
\hline
\end{tabular}

Source: IHAT for SHA 2011. 


\section{Notes}

1. Measuring health and its improvement or deterioration is an important aspect of health economics and statistics, as is reflected, for example, in such measures as life expectancy, healthy life years (HLY) and quality/disability-adjusted life years (QALY, DALY). SHA 2011, like SHA 1.0, does not aim at such measures, but at measurements of health care expenditure. This means that the SHA accounting framework is part of a larger model, in which several determinants of health, one of them being the provision of health care, play a crucial role.

2. SHA describes the international concept and boundaries of health accounts. However, countries have their own responsibility to define what is in or out of the national health care services boundary. As a result, national boundaries may deviate from the international boundaries.

3. A set of tables to present the interaction of these three axes is included in Chapter 15.

4. Intermediate consumption consists of the value of the goods and services consumed as inputs by the process of provision, excluding the cost of fixed assets whose consumption is recorded as consumption of fixed capital.

5. Occupational health care is treated by SNA as intermediate consumption and therefore not included in the consumption of health care services by households. In contrast, SHA includes occupational health care as health expenditure because of the health benefits for employees. It is governed in most countries by detailed regulations. Occupational health care includes surveillance of employee health (routine medical check-ups) and therapeutic care (including emergency health care services) on or off business premises. The expenditure incurred in occupational health care can be approximately estimated as the cost of the personnel involved.

6. Occupations in traditional and complementary medicine whose practice requires an extensive understanding of the benefits and applications of traditional and complementary therapies, developed as the result of extended formal study of these techniques as well as human anatomy and elements of modern medicine, are classified in unit group 2230, Traditional and complementary medicine professionals. Those whose practice requires a less extensive understanding, which is based on relatively short periods of formal or informal education and training or that is developed informally through the traditions and practices of the communities where they originated, are included in Unit group 3230, Traditional and complementary medicine associate professionals.

7. For details about the accounting of non-observed health activities see OECD (2002b) and United Nations (2008a).

8. Here, two problems appear. The first concerns data availability. Despite the progress in the measurement of health care provision by households, few data about health care provided at home by relatives or neighbours are available. Furthermore, household provision consists of a large variety of different activities that are presently not standardised (see Eurostat, 2003).

9. The basic activities of daily living (ADL) consist of certain self-care tasks that could be supported or provided by a family member if the person is not able to do them by him/herself: personal hygiene, dressing and undressing, eating, transferring from bed to chair and back, voluntarily controlling urinary and faecal discharge, or moving around (as opposed to being bedridden).

10. SNA aims to measure all inputs (productive activities) related to the production of goods and services and to balance this with all outputs either used by industries, consumed, invested or exported. The view of consumption in SHA requires a different approach than the view of production in SNA. Therefore, the value of the consumption of medical goods is measured at purchasers' prices including total VAT within the core accounting framework. In contrast, in SNA, "The output of retailers is measured by the total value of the trade margins realised on the goods they purchase for re-sale (valued at actual prices)." The reason is that in SNA the production of pharmaceuticals is measured as output of the pharmaceutical industry. In general, the productive activity of pharmacies is restricted to distribution. The cumulative values of the production of pharmaceuticals by industries, transportation, and wholesalers of pharmaceuticals would have to be incorporated to measure the total production value of pharmaceuticals.

11. Prices of health care services are dealt with in more detail in Chapter 13.

12. The difference between depreciation and consumption of fixed capital can be important, due to the historic cost versus opportunity cost principle. To avoid confusion, the term "consumption of fixed capital" is used in SNA to distinguish it from "depreciation" as typically measured in business accounts (SNA 2008, 1.66). 
13. Products that are excluded from the SHA boundaries might be considered by some countries for their inclusion in the complementary expenditure framework for analytical use.

14. Chapter 5 proposes a memorandum item for health promotion in multi-sectoral settings, notably to capture joint intervention of the health system and other branches, e.g. alcohol level detection in drivers.

15. If it is not possible to separate the aesthetic purpose from the medical purpose, this should be documented under metadata.

16. Instrumental Activities of Daily Living (IADL) comprises activities such as shopping, cooking, doing laundry, managing household finances and housekeeping. To perform these activities, medical, paramedical or nursing knowledge is not required.

17. In case a separation is not possible between the health care components and the social care components, a clear description in the metadata is required.

18. For example, the Primary Health Care model as articulated at Alma-Ata explicitly stated the need for a comprehensive health strategy that not only provided health services but also addressed the underlying social, economic and political causes of poor health. Call for global action on the social determinants of health with the aim of achieving health equity see WHO (2008a).

19. Estimating current health expenditure according to disease is comparable with direct health cost in Cost-of-Illness accounts (COI). One should note that direct non-health cost, such as transportation and lodging for family members if the health provider is far from home or childcare for dependent children during hospital stay, is not included. COI may consider different time frames for cost estimation: the annual time frame (prevalence-based) or the lifetime frame (incidence-based). Because prevalence-based models have a simpler data requirement, they have been more widely used than incidence-based ones (see Chapter 9).

20. COI studies are not standard in their content, so that the indirect costs are not always included and the coverage of the indirect costs is not unified. See Polder (2001).

SNA 2008, Chapter 29, describes such an approach that balances supply and use of health care goods and services in the outline of an input-output model. This is further discussed in Annex B.

21. SHA 2011 aims to measure only the activities of the providers of health care. The intermediate use of health care products and services by other industries are not considered, because it would require the compilation of a complete input-output table.

22. The financing interface is developed in detail in Chapters 7 and 8.

23. In Chapter 8 , Table 8.3 shows a possible presentation of the operating balance of health care financing schemes and discusses the possible accounting of loans that may be taken to cover the expenditure of the financing schemes not balanced by their revenues. 


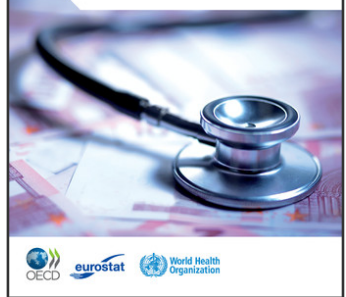

\section{From:}

A System of Health Accounts

2011 Edition

Access the complete publication at:

https://doi.org/10.1787/9789264116016-en

\section{Please cite this chapter as:}

OECD/World Health Organization/Eurostat (2011), "Global Boundaries of Health Care", in A System of Health Accounts: 2011 Edition, OECD Publishing, Paris.

DOI: https://doi.org/10.1787/9789264116016-6-en

This work is published under the responsibility of the Secretary-General of the OECD. The opinions expressed and arguments employed herein do not necessarily reflect the official views of OECD member countries.

This document and any map included herein are without prejudice to the status of or sovereignty over any territory, to the delimitation of international frontiers and boundaries and to the name of any territory, city or area.

You can copy, download or print OECD content for your own use, and you can include excerpts from OECD publications, databases and multimedia products in your own documents, presentations, blogs, websites and teaching materials, provided that suitable acknowledgment of OECD as source and copyright owner is given. All requests for public or commercial use and translation rights should be submitted to rights@oecd.org. Requests for permission to photocopy portions of this material for public or commercial use shall be addressed directly to the Copyright Clearance Center (CCC) at info@copyright.com or the Centre français d'exploitation du droit de copie (CFC) at contact@cfcopies.com. 